\title{
Receptor guanylyl cyclase B-mediated cGMP signalling controls axon bifurcation of cranial sensory ganglion neurons at the embryonic hindbrain
}

\author{
Gohar Ter-Avetisyan, Fritz G Rathjen ${ }^{\dagger}$, Hannes Schmidt ${ }^{* \dagger}$
}

From 6th International Conference on cGMP: Generators, Effectors and Therapeutic Implications

Erfurt, Germany. 28-30 June 2013

\section{Background}

Axonal branching is a key principle for the establishment of neuronal circuitry that allows an individual neuron to innervate several target areas thus providing a physical framework for parallel processing of information. Our previous search for molecular determinants of axonal branching unravelled a cGMP signalling pathway in embryonic dorsal root ganglion (DRG) neurons composed of the ligand C-type natriuretic peptide (CNP), the receptor guanylyl cyclase B (GC-B, also termed Npr2), and the cGMP-dependent protein kinase I $\alpha$ (cGKI $\alpha$ ) that is essential for the bifurcation of sensory axons at the dorsal root entry zone of the spinal cord. Absence of any of these components causes a complete loss of bifurcation where sensory axons only turn in either a rostral or a caudal direction (Figure 1A). Consequently mutant mice reveal a

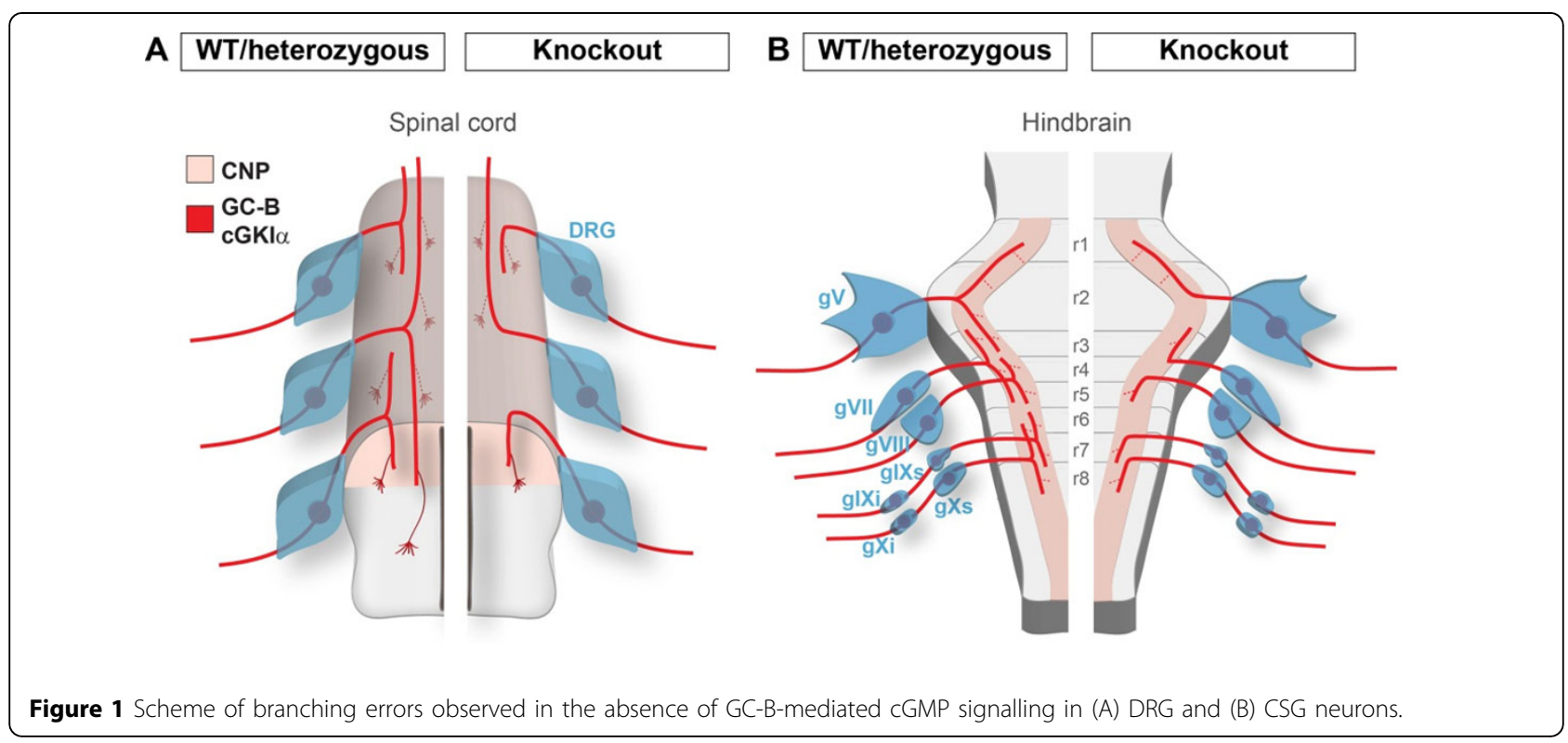

\footnotetext{
* Correspondence: hannes.schmidt@mdc-berlin.de

† Contributed equally

Developmental Neurobiology Group, Max Delbrück Center for Molecular

Medicine, Berlin, Germany
} 
reduced synaptic input onto second-order neurons in the dorsal horn of the spinal cord.

\section{Results}

To examine whether the cGMP signalling system that underlies axon bifurcation in DRG neurons may also extend to other neuronal subpopulations we generated a GC-B-lacZ reporter mouse line for a detailed analysis of the GC-B expression pattern during embryonic development. A strong expression of GC-B that correlated with the localization of cGKI $\alpha$ was detected in neurons of all cranial sensory ganglia (CSG) at early embryonic stages when their central afferents enter the brainstem. Furthermore, a complimentary distribution of the ligand $\mathrm{CNP}$ at the entry zones of these axons in the hindbrain was observed.

To analyze the impact of GC-B-mediated cGMP signalling on axonal branching of CSG neurons we applied a genetic strategy for sparse labelling of GC-B-expressing neurons. For this purpose we generated a mouse mutant (GC-B-CreERT2) encoding a tamoxifen-inducible variant of Cre recombinase under control of the GC-B promoter that in combination with a conditional alkaline phosphatase reporter (Z/AP) enables the visualization of individual neurons within the genetically defined subset of GC-Bexpressing cells. Comparing the branching patterns of GC-B heterozygous mice which resemble the wild-type phenotype with those of homozygous GC-B-deficient animals we found that in the absence of GC-B the bifurcation of axons of CSG neurons upon entering the hindbrain is impaired and only an ascending or a descending arm is formed (Figure 1B).

\section{Conclusion}

Our data demonstrate that neurons of CSG - similar to DRG neurons - use GC-B-mediated cGMP signalling to trigger axonal bifurcation.

Published: 29 August 2013
doi:10.1186/2050-6511-14-S1-P71

Cite this article as: Ter-Avetisyan et al:: Receptor guanylyl cyclase B-mediated CGMP signalling controls axon bifurcation of cranial sensory ganglion neurons at the embryonic hindbrain. BMC Pharmacology and Toxicology 2013 14(Suppl 1):P71.
Submit your next manuscript to BioMed Central and take full advantage of:

- Convenient online submission

- Thorough peer review

- No space constraints or color figure charges

- Immediate publication on acceptance

- Inclusion in PubMed, CAS, Scopus and Google Scholar

- Research which is freely available for redistribution

Submit your manuscript at www.biomedcentral.com/submit 